\title{
Twilight foraging enables European shags to survive the winter across their latitudinal range
}

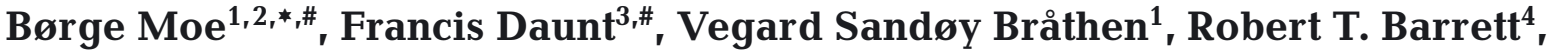 \\ Manuel Ballesteros ${ }^{5}$, Oskar Bjørnstad ${ }^{6}$, Maria I. Bogdanova ${ }^{3}$, Nina Dehnhard ${ }^{1}$, \\ Kjell Einar Erikstad ${ }^{5,7}$, Arne Follestad ${ }^{1}$, Sindri Gíslason ${ }^{8}$, Gunnar Thor Hallgrimsson ${ }^{9}$, \\ Svein-Håkon Lorentsen ${ }^{1}$, Mark Newell ${ }^{3}$, Aevar Petersen ${ }^{10}$, Richard A. Phillips ${ }^{11}$, \\ Sunna Björk Ragnarsdóttir ${ }^{8,12}$, Tone Kristin Reiertsen ${ }^{5}$, Jens Åström ${ }^{1}$, Sarah Wanless ${ }^{3}$, \\ Tycho Anker-Nilssen ${ }^{1}$

\begin{abstract}
${ }^{1}$ Norwegian Institute for Nature Research (NINA), PO Box 5685 Torgarden, 7485 Trondheim, Norway
${ }^{2}$ Department of Biology, Norwegian University of Science and Technology, 7491 Trondheim, Norway

${ }^{3}$ UK Centre for Ecology \& Hydrology, Bush Estate, Penicuik EH26 0QB, UK

${ }^{4}$ Department of Natural Sciences, Tromsø University Museum, 9037 Tromsø
\end{abstract} \\ ${ }^{5}$ Norwegian Institute for Nature Research (NINA), FRAM - High North Research Centre for Climate and the Environment, \\ PO Box 6606 Langnes, 9296 Tromsø, Norway \\ ${ }^{6}$ Grødheimvegen 18, 4280 Skudeneshavn, Norway \\ ${ }^{7}$ Centre for Biodiversity Dynamics, Department of Biology, Norwegian University of Science and Technology, \\ 7491 Trondheim, Norway \\ ${ }^{8}$ Southwest Iceland Nature Research Centre (SINRC), 245 Sudurnesjabaer, Iceland \\ ${ }^{9}$ Department of Life and Environmental Sciences, University of Iceland, 102 Reykjavík, Iceland \\ ${ }^{10}$ Brautarland 2, 108 Reykjavík, Iceland \\ ${ }^{11}$ British Antarctic Survey, Natural Environmental Research Council, High Cross, Cambridge CB3 0ET, UK \\ ${ }^{12}$ Icelandic Institute of Natural History, Borgum, 600 Akureyri, Iceland
}

\begin{abstract}
Species breeding at high latitudes face a significant challenge of surviving the winter. Such conditions are particularly severe for diurnal marine endotherms such as seabirds. A critical question is therefore what behavioural strategies such species adopt to maximise survival probability. We tested 3 hypotheses: (1) they migrate to lower latitudes to exploit longer day length ('sun-chasing'), (2) they forage at night ('night-feeding'), or (3) they target high-quality food patches to minimise foraging time ('feasting'). We studied the winter migration and foraging strategies of European shags Phalacrocorax aristotelis from 6 colonies across a latitudinal gradient from temperate regions to north of the Arctic Circle using geolocators deployed over 11 winters. We found evidence for 'sun-chasing', whereby average southerly movements were greatest from colonies at higher latitudes. However, a proportion of individuals from higher latitudes remained resident in winter and, in the absence of daylight, they foraged during twilight and only very occasionally during the night. At lower latitudes, there was little evidence that individuals migrated south, nocturnal feeding was absent, and twilight feeding was infrequent, suggesting that there was sufficient daylight in winter. There was no evidence that winter foraging time was lowest at higher latitudes, as predicted by the 'feasting' hypothesis. Our results suggest that shags adopt different behavioural strategies to survive the winter across their latitudinal range, dictated by the differing light constraints. Our study highlights the value of multi-colony studies in testing key hypotheses to explain population persistence in seabird species that occur over large latitudinal ranges.
\end{abstract}

KEY WORDS: Winter ecology · Phalacrocorax aristotelis · Partial migration · Latitudinal gradient · Foraging effort $\cdot$ Geolocation $\cdot$ Data logger

${ }^{*}$ Corresponding author: borge.moe@nina.no

\#These authors contributed equally to this work

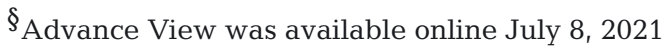

(C) The authors 2021. Open Access under Creative Commons by Attribution Licence. Use, distribution and reproduction are unrestricted. Authors and original publication must be credited.

Publisher: Inter-Research · www.int-res.com 


\section{INTRODUCTION}

At high latitudes, animals typically schedule breeding activities in the spring and summer to coincide with favourable environmental conditions (Lack 1968, Stearns 1992). Long-lived species must achieve this annual deadline by surviving the winter when faced with a number of challenges, including increased daily energy requirements, higher frequency of extreme weather events and, for diurnally foraging species, shortened day length (Newton 1998). Across the range of widely distributed species, populations may experience a wide variety of winter conditions. In many cases, the conditions are closely tied to latitude, and latitudinal gradients in environmental severity are particularly marked in winter. The most predictable variation in physical conditions is day length and associated light levels, which show systematic changes with latitude and season. As such, a critical question in understanding a species' persistence across its range is how individuals breeding at higher latitudes survive the winter, in particular diurnal species that winter in regions experiencing the polar night where light levels are very low for a long period of the year.

Winter conditions at higher latitudes are expected to be severe for diurnal marine endotherms, such as seabirds, because of the higher energetic requirements at low temperatures, and greatly reduced day length and overall light levels (Grémillet et al. 1999, Daunt et al. 2006). Animal-borne instruments that record location and activity, in particular lightlevel geolocators (Wilson et al. 1992, Hill 1994), provide opportunities to quantify migration and foraging strategies of seabirds and other marine endotherms throughout the annual cycle to establish the behavioural strategies individuals from such species employ to survive the winter.

Individuals breeding at high latitudes may migrate to locations where day length is longer to exploit greater light levels. For example, trans-equatorial migrants may experience an 'endless summer' (e.g. Arctic tern Sterna paradisaea, Egevang et al. 2010; Sabine's gull Xema sabini, Stenhouse et al. 2012; long-tailed skua Stercorarius longicaudus, Gilg et al. 2013). Most seabird species remain in the same hemisphere throughout the year (Frederiksen et al. 2012, 2016, Hanssen et al. 2016, Fayet et al. 2017) and may increase day length by migrating to lower latitudes ('sun-chasing' hypothesis, Daunt et al. 2006). Several studies using geolocation technology have demonstrated evidence for migration to lower latitudes in seabirds (e.g. Fort et al. 2013, McFarlane
Tranquilla et al. 2013). These include Arctic populations that migrate south of the Arctic Circle (e.g. White et al. 2013), enabling individuals to avoid the polar night. Seabirds may migrate to lower latitudes for reasons other than light levels, such as food availability, weather conditions and, at higher latitudes, sea ice cover (Fort et al. 2013). A useful approach in establishing whether behavioural strategies to combat reduced light levels are a key factor in enabling seabirds breeding at high latitudes to survive the winter is to study multiple populations across a latitudinal gradient, since light levels change much more predictably with latitude than other environmental conditions. In doing so, it is important to note that not all individuals may adopt the same migration strategy. Partial migration occurs where a proportion of individuals remains resident while the remainder migrates. This type of migration is extremely common in nature, including in seabirds (Chapman et al. 2011). The 'sun-chasing' hypothesis predicts that where partial migration occurs, population average migratory movements to lower latitudes increase with increasing latitude of the breeding colony.

A second strategy whereby individuals may respond to shortened day length in winter is by foraging at night if they are unable to obtain their daily food requirements in daytime or twilight ('nightfeeding' hypothesis, Grémillet et al. 2005a). In great cormorants Phalacrocorax carbo that breed in Greenland $\left(69^{\circ} \mathrm{N}\right)$ and exhibit partial migration, with some individuals remaining resident and others migrating to the south of the country $\left(59^{\circ} \mathrm{N}\right.$, White et al. 2013), $46 \%$ of dive bouts take place during the night in December (Grémillet et al. 2005a, White et al. 2011). Common eiders Somateria mollissima breeding on Svalbard $\left(79^{\circ} \mathrm{N}\right)$ may depart as late as the end of December (Hanssen et al. 2016), and all foraging must occur during the night from the beginning of November until departure. The 'sun-chasing' and 'night-feeding' hypotheses may be adopted simultaneously, whereby an individual breeding at high latitudes may move to lower latitudes and also feed at night, if constraints on the ability to migrate preclude daily energy requirements to be attained through diurnal feeding alone. Partial migration may be apparent, whereby individuals span a range of migration movements and associated partitioning of foraging in the day, in twilight and at night. In such circumstances, average population responses would be predicted to show a linear relationship in nighttime foraging with latitude if day length is a key factor in determining the survival strategies of seabirds in winter. 
A third potential strategy whereby diurnally feeding seabirds survive the winter is by targeting high quality or abundant food, thereby enabling individuals to attain their daily energy requirements more rapidly and allowing them to survive during periods of reduced light ('feasting' hypothesis, Grémillet et al. 1999). This strategy may be possible in winter since individuals are less constrained to remain close to a central place and can therefore relocate to areas of high food availability more readily than in the breeding season, when they must repeatedly return to the nest for incubation and chick-rearing duties. Research on populations of great cormorants in northwest Greenland suggests that they target high-quality food patches which enable them to survive the low light levels at these latitudes (Grémillet et al. 1999, White et al. 2013). If this strategy predominates, populations may adopt strategies opposite to that predicted by the 'sun-chasing' hypothesis, i.e. migrate to higher latitudes in winter in order to locate high-quality or abundant food. Availability of highquality food may also preclude the need for individuals to forage at night. Overall, to what extent diurnally foraging species employ these different behavioural strategies to overcome constraints on day length and light levels in winter at high latitudes remains unclear. Multi-colony studies across a latitudinal gradient offer a powerful opportunity to establish the relative importance of migration to lower latitudes to exploit longer day length ('sun-chasing' hypothesis), foraging at night ('night-feeding' hypothesis) or targeting more profitable food patches to minimise foraging time ('feasting' hypothesis).

In this study, we tested these 3 hypotheses in a multi-colony study across the latitudinal range of the European shag $P$. aristotelis (hereafter shag). The shag is a pursuit-diving, diurnal, visual-foraging seabird with high energetic costs associated with its wettable plumage (Wanless \& Harris 1997, Wanless et al. 1999, Grémillet et al. 2005b). Previous work using geolocation devices showed that shags breeding in temperate regions $\left(55^{\circ} \mathrm{N}\right)$ dedicated over $90 \%$ of available daylight to foraging during the winter solstice and that foraging was almost completely absent at night (Daunt et al. 2006, 2014). Shags are distributed from north Africa to northern Europe, at latitudes ranging from 30 to $71^{\circ} \mathrm{N}$, with $\sim 10 \%$ breeding at colonies north of the Arctic Circle (Wanless \& Harris 1997, Fauchald et al. 2015). The observed pattern of winter foraging in temperate regions therefore raises the question of how shags at high latitudes obtain sufficient food to survive the winter, when available light is much more limited. Evidence from ring recoveries and live sightings of colour-marked individuals indicates that shags are partial migrants (Bakken et al. 2003, Grist et al. 2014). Ringing studies also provide preliminary evidence that 'sun-chasing' increases with latitude, with shags breeding in northern Norway migrating many hundreds of $\mathrm{km}$ south along the Norwegian coast during the winter (Bakken et al. 2003). This strategy enables migrating individuals to avoid the polar night, which would be experienced by those that remain resident. In contrast, migrant shags from Scotland and Iceland show more limited movements (Lilliendahl \& Solmundsson 2006, Grist et al. 2014). To compare variation in movements across a latitudinal gradient using different methods, however, remains challenging, and no studies have compared timing and extent of foraging with latitude to test the 'night-feeding' and 'feasting' hypotheses. We therefore aimed to quantify winter migration and foraging strategies using geolocators in shag colonies spread across the species' breeding range in the NE Atlantic. We used locational and behavioural data from birds from these colonies to test 3 key predictions from the 'sun-chasing', 'night-feeding' and 'feasting' hypotheses: (1) average southerly displacement of southerly migration will increase with increasing latitude ('sun-chasing'); (2) extent of foraging at night will increase with increasing latitude ('night-feeding'); (3) foraging time will decrease with increasing latitude ('feasting').

\section{MATERIALS AND METHODS}

\subsection{Study design and geolocator data}

The study was carried out in 7 colonies in Scotland (Isle of May, 56 $11^{\prime} \mathrm{N}, 02^{\circ} 33^{\prime} \mathrm{W}$ ), Iceland (Flatey, 65 $22^{\prime} \mathrm{N}, 22^{\circ} 54^{\prime} \mathrm{W}$ and Melrakkaey, 64 $59^{\prime} \mathrm{N}$, $23^{\circ} 18^{\prime} \mathrm{W}$ ) and Norway (Jarsteinen, $59^{\circ} 09^{\prime} \mathrm{N}, 05^{\circ} 10^{\prime} \mathrm{E}$, Sklinna, $65^{\circ} 13^{\prime} \mathrm{N}, 10^{\circ} 58^{\prime} \mathrm{E}$, Røst $67^{\circ} 27^{\prime} \mathrm{N}, 11^{\circ} 55^{\prime} \mathrm{E}$, and Hornøya, $70^{\circ} 23^{\prime} \mathrm{N}, 31^{\circ} 09^{\prime} \mathrm{E}$ ). The 2 colonies in Iceland are located only $47 \mathrm{~km}$ apart in Breiðafjörður, and we merged their data under the name Breiðafjörður (Fig. 1). We deployed geolocators with immersion sensors on adult shags during incubation or chick rearing in the breeding seasons 2006-2009 and 2011-2019 (Table 1 and Tables S1-S3 in the Supplement at www.int-res.com/articles/suppl/m676p145_ supp.pdf). The geolocators were retrieved the following year or in later years. They weighed $0.1-0.5 \%$ of the birds' body mass and were attached to a leg ring with cable ties. Although we did not undertake a formal analysis of device effects in this study, loggers 
representing $0.23 \%$ body mass did not significantly affect diving ability in the closely related great cormorant (Ropert-Coudert et al. 2009).

All the geolocator data were processed according to the procedure developed for the SEATRACK project (Bråthen et al. 2021). In short, this procedure automatically identifies twilight events from raw light data using the 'twilightCalc' function in the 'GeoLight' package (Lisovski \& Hahn 2012), and applies a set of filters on twilight events (remove or move events creating false day/night or noise) and positions (speed, distribution limits, angle filter). Calibration (assigning sun elevation angle) is done by inspecting

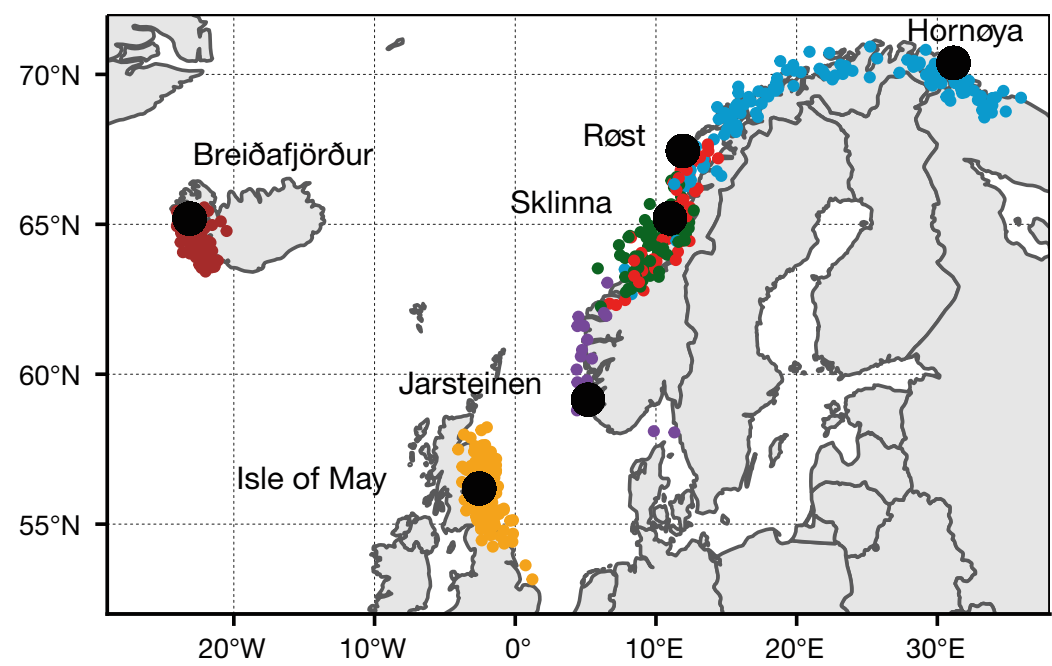

Fig. 1. Median positions in December by European shags tracked with geolocators from Hornøya (blue), Røst (red), Sklinna (green), Breiðafjörður (brown), Jarsteinen (purple) and Isle of May (orange)

Table 1. Study colonies and number of median positions in December obtained from individual European shags tracked with geolocators. All positions had corresponding immersion data from which we calculated time spent foraging. Breiðafjörður includes the colonies Flatey (2006-2007) and Melrakkaey (2015-2018)

\begin{tabular}{|lcccccc|}
\hline $\begin{array}{l}\text { Year } \\
\text { tracked }\end{array}$ & $\begin{array}{c}\text { Isle } \\
\text { of May }\end{array}$ & Jarsteinen & $\begin{array}{l}\text { Breiða- } \\
\text { fjörður }\end{array}$ & Sklinna & Røst & Hornøya \\
\hline $2006-2007$ & 16 & & 10 & & 6 & 14 \\
$2007-2008$ & 11 & & 5 & & 1 & 8 \\
$2008-2009$ & & & & 1 & & 1 \\
$2011-2012$ & & & & 1 & & 24 \\
$2012-2013$ & & & & 1 & & 22 \\
$2013-2014$ & & & & 19 & 18 & \\
$2014-2015$ & 20 & & 9 & 13 & 16 & 12 \\
$2015-2016$ & 29 & & 22 & 19 & 12 & 20 \\
$2016-2017$ & 29 & 8 & 8 & 8 & 4 & 17 \\
$2017-2018$ & 23 & 7 & 61 & 79 & 57 & 128 \\
$2018-2019$ & 15 & 3 & 37 & 39 & 38 & 83 \\
Positions & 143 & 18 & 13 & & & \\
N ind. & 58 & & & & & \\
\hline
\end{tabular}

latitude vs. time plots for each track for a range of sun elevation angles (Hanssen et al. 2016, van Bemmelen et al. 2017, 2019), before positions are doubly smoothed to reduce influence of inaccurate positions and compensate for movements (Fox 2010, 2015). alibration is the only step with expert assessment, erwise the algorithm runs automatically. Bråthen al. (2021) provided further details about this procere. Although some of the shag logger data had processed as part of an earlier study (Daunt et 2014), for consistency, all raw light and immersion data were analysed according to the SEATRACK protocol (Bråthen et al. 2021).

We conducted 2 additional steps of data manipulations for this study, to accompany all the immersion data with more realistic positional data. First, we applied a polygon filter to discard positions far from the coast (Fig. S1 in the Supplement). Second, we replaced these positions using the 'fillMissing' function in the 'baytrends' package in R (Murphy et al. 2020), which simply adds daily positions with a linear interpolation between the positions before and after the gap. We did the same for gaps in the positional data occurring approximately 1 wk around the winter solstice at the highest latitudes $\left(\geq 70^{\circ} \mathrm{N}\right)$. We then calculated median positions for December for each individual.

\subsection{Immersion data and time spent foraging}

The geolocator saltwater immersion sensors record the amount of time spent in the water. We used this as an accurate measure of time spent foraging since shags almost exclusively enter the water to feed (Daunt et al. 2006). Samples of time spent in water (number of 'wet' samples during $10 \mathrm{~min}$ intervals; Table S3) were standardized to proportion values between 0 (all dry/ 0 min wet) and 1 (all wet/10 min wet) across all geolocator models and assigned to a light category: daylight (or daytime, sun above the horizon), civil twilight (sun position relative to the horizon between 0 and $-6^{\circ}$ ), nautical 
twilight (sun between -6 and $-12^{\circ}$ ) or night (or nighttime, sun below $-12^{\circ}$; see Fig. 5). Note that our category 'night' also includes astronomical twilight (sun between -12 and $-18^{\circ}$, NOAA 2020). We used the 'getSunlightTimes' function in R ('suncalc' package, Thieurmel \& Elmarhraoui 2019) to obtain these categories from the time recorded and the geographic position of the individual. Since the daily positions of geolocators are inherently inaccurate (ca. $185 \mathrm{~km}$ mean error, Phillips et al. 2004), median position in December (see Section 2.3) represented the geographic position at each 10 min recording instead of daily estimated positions, to avoid unrealistically high daily variation in estimated light categories. We then summed the wet time (foraging time) in each light category to obtain the total time spent foraging in each light category for each individual on each day. Based on the daily sums, we finally obtained the median time spent foraging in each light category and then the proportion of time spent foraging within each light category (time spent foraging/ duration of light category) for each individual in December.

\subsection{Spatial calculations}

This study focusses on the winter, and we used the median position in December (the darkest month) for each individual to map individual migration patterns. Some birds were tracked over multiple years, but since geolocators have less memory devoted to immersion compared to light, they may fail to record immersion data over the entire tracking period. This study only includes positional data accompanied by immersion data, for which we obtained a total of 486 median December positions for 268 individuals (Table 1). Change in latitude, or latitude displacement from the colony, was calculated as the median latitude in December minus colony latitude. Distance from median December position to breeding colony was calculated as distance by sea using the 'gridDistance' function in the 'raster' package (Hijmans 2020), after moving median December positions located on land to the nearest point on the coastline.

\subsection{Statistical analyses}

We used linear mixed-effects models (LMMs) fitted with restricted maximum likelihood for normally distributed data with individual and year as random effects ('lmer' function, 'lme4' package, Douglas et al. 2015). Summary statistics with p-values were obtained with Satterthwaite's degrees of freedom ('ImerTest' package, Kuznetsova et al. 2017). Latitude displacement from colony, distance from colony and total time spent foraging were dependent variables in separate models, with colony ID as a fixed effect factor. Latitude in December was also fitted as a covariate to models of total time spent foraging. We used generalized mixed-effects models (beta regression) fitted with maximum likelihood for beta distributed data (family = beta) with individual and year as random effects ('glmmTMB' package, Brooks et al. 2017). Proportion of time spent foraging within light categories (values between 0 and 1) was modelled with latitude as a covariate and individual and year as random effects. First we tested for an interaction between latitude and light category. Then we tested whether proportion of time spent foraging increased with increasing latitude in separate models on civil and nautical twilight. For all mixedeffects models, statistical significance was obtained by comparing models with and without the variable or interaction term, fitted (beta regression) or refitted (LMMs) with maximum likelihood.

The relationships between median latitude in December and time spent foraging and proportion of foraging within different light categories were visualized with smoothed non-parametric regression (LOESS, 'loess' function, 'stats' package, R Core Team 2020). Predicted values and standard errors were obtained for every $0.5^{\circ}$ between 54 and $72^{\circ} \mathrm{N}$ ('predict' function, 'stats' package, R Core Team 2020). Predictive lines and confidence intervals were plotted graphically with the 'geom_smooth' function ('ggplot2' package, Wickham 2016). All statistical analyses and graphs were made using $\mathrm{R}$ version 3.6.3 ( $R$ Core Team 2020), and estimates are provided with \pm 1 SE unless otherwise stated.

\section{RESULTS}

\subsection{Movement patterns}

Shags were located in December a mean of $227 \mathrm{~km}$ from the breeding colony, and $75 \%$ of all positions were within $253 \mathrm{~km}$ of the colony. However, there was considerable variation among individuals, with a range spanning 0-1565 $\mathrm{km}$ from the breeding colony (Figs. 1 \& 2). Such marked variation in distance from colony between individuals was apparent at all 
colonies, suggesting that all populations were partially migratory (Fig. 1).

\section{2. 'Sun-chasing' hypothesis}

Under the 'sun-chasing' hypothesis, we predicted that average latitudinal southerly displacement will increase with increasing latitude of a colony. We found partial support for this prediction such that latitudinal displacement in December differed among colonies (LMM: $\mathrm{n}=487, \Delta \log \mathrm{Lik}=50.6, \Delta \mathrm{AIC}=70.3$, $\chi^{2}=104.2, \mathrm{df}=5, \mathrm{p}<0.001$; Fig. 2A) and the greatest displacement was seen for the 2 northernmost colonies (Røst and Hornøya). However, we did not see a consistent relationship with colony latitude as predicted by the hypothesis (Fig. 2A). The greatest departure from the prediction of the 'sun-chasing' hypothesis was observed in Jarsteinen shags, which migrated on average in a northerly direction with median location in December $1.41 \pm 0.34^{\circ}$ north of the breeding colony (LMM, $t_{262}=4.15, \mathrm{p}<0.001$; Fig. 2A). Further, shags from Røst showed a greater latitudinal displacement than those from Hornøya $\left(2.20 \pm 0.22\right.$ and $1.41 \pm 0.15^{\circ}$, respectively; LMM, Røst: $t=-10.2$, df $=129.0, \mathrm{p}<0.001$; Hornøya: $t=$ -9.1, df $=55.2, \mathrm{p}<0.001$ ), despite the Røst colony being located farther south. Latitudinal displacements led to equivalent changes in day length gain (Fig. 2B) and distance from the colony in most cases (Fig. 2C). The main departure from this close link between latitudinal displacement, day length gained and distance from colony was with Hornøya birds. Shags from this colony travelled further than Røst birds on average, which did not match the difference in latitudinal displacement (Fig. 2A).
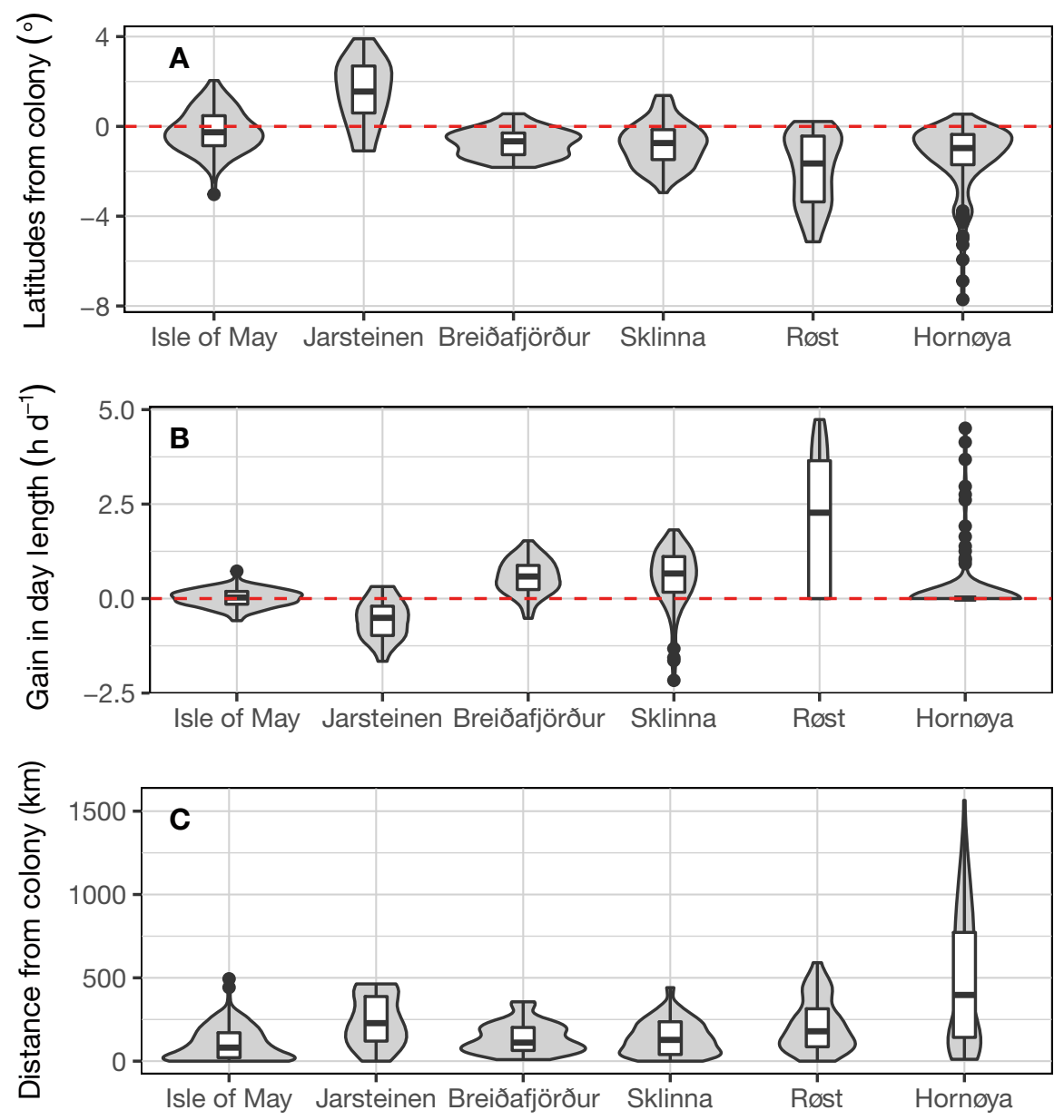

Fig. 2. (A) Latitudinal displacement from breeding colony $\left({ }^{\circ}\right)$, (B) gain in day length $\left(\mathrm{h} \mathrm{d}^{-1}\right)$ and $(\mathrm{C})$ distance from colony $(\mathrm{km})$ in December by European shags tracked with geolocators from the different study colonies (see Fig. 1). Colonies are ordered by increasing latitude. The violin plots show the median of the data bound by an interquartile range (IQR) box, along with the kernel probability density of the data at different values. The vertical whiskers extend to the smallest or highest value within $1.5 \times$ IQR from the box, and points beyond the whiskers are outliers 


\section{3. 'Night-feeding' hypothesis}

We found limited support for the prediction that the extent of foraging at night will increase with increasing colony latitude. Nighttime foraging was absent in the populations from the Isle of May, Jarsteinen and Breiðafjörður, but the proportion of nighttime foraging was indeed greater at the higher latitude colonies of Hornøya, Røst and Sklinna (Fig. 3). However, nighttime foraging at these colonies represented just $5 \%$ of total daily foraging. Foraging occurred mainly (>75\%) during daytime in shags from the populations Isle of May, Jarsteinen, and Breiðafjörður (Fig. 3). In birds from Sklinna and Røst, the average proportion of daytime foraging in December was $\sim 50 \%$, while it was only $6 \%$ in the Hornøya population (Fig. 3). Crucially, foraging during civil twilight increased strongly with increasing colony latitude, and represented a substantially larger proportion of daily foraging time than nighttime foraging at higher colony latitudes (Fig. 3).

The time shags spent foraging and the proportion of time spent foraging within each light category (daytime, civil twilight, nautical twilight, nighttime) related strongly to their median latitude in December (Fig. 4). Smoothed non-parametric regression (LOESS) showed that the relationship between time spent foraging and latitude was non-linear and differed substantially between light categories (Fig. 4A). Shags foraged $5.6 \pm 0.08 \mathrm{~h} \mathrm{~d}^{-1}$ during daytime at $55^{\circ} \mathrm{N}$. Daytime foraging strongly declined with latitude and reached zero at $67.6^{\circ} \mathrm{N}$, where daylight becomes absent (Fig. 5). In contrast, foraging time during civil twilight was $0.12 \pm 0.04 \mathrm{~h} \mathrm{~d}^{-1}$ at $55^{\circ} \mathrm{N}$, increased to $4.0 \pm 0.03 \mathrm{~h} \mathrm{~d}^{-1}$ at $69^{\circ} \mathrm{N}$ and then decreased (Fig. 4A) . The relationship between proportion of time spent foraging and latitude differed among light categories (beta regression, $\mathrm{n}=1838, \Delta \log \mathrm{Lik}=-172, \Delta \mathrm{AIC}=338$, $\chi^{2}=343, \mathrm{df}=3, \mathrm{p}<0.001 ;$ Fig. 4B). The proportion of daytime spent foraging was comparatively consistent at all latitudes where daylight was available (Fig. 4B). The proportion of available civil twilight hours spent foraging increased strongly with increasing latitude (beta regression: $\mathrm{n}=487, \Delta \log \mathrm{Lik}=-225, \Delta \mathrm{AIC}=448$, $\chi^{2}=450, \mathrm{df}=1, \mathrm{p}<0.001$; Fig. $4 \mathrm{~B}$ ) and was 26 and $81 \%$ at 60 and $70^{\circ} \mathrm{N}$, respectively (Fig. 4B). Time spent foraging during nautical twilight was very low at low latitudes and increased exponentially at high latitude, with $0.23 \pm 0.03$ and $1.14 \pm 0.03 \mathrm{~h} \mathrm{~d}^{-1}$ at 65 and $70^{\circ} \mathrm{N}$, respectively (Fig. 4A). Further, the proportion of available nautical twilight hours spent foraging increased with increasing latitude (beta regression: $\mathrm{n}=487, \Delta \log \mathrm{Lik}=-92, \Delta \mathrm{AIC}=181, \chi^{2}=183, \mathrm{df}=1$, p $<0.001$; Fig. 4B) and reached $27 \%$ at $70^{\circ} \mathrm{N}$ (Fig. 4B). Time spent foraging during the night was lowest of all light categories but increased slightly at high latitudes and was $0.30 \pm 0.05 \mathrm{~h} \mathrm{~d}^{-1}$ at $70^{\circ} \mathrm{N}$ (Fig. 4A). Thus, there was very little foraging among shags at night in December at all latitudes where they were located. The results therefore indicate that foraging during twilight increased strongly with increasing latitude and comprised a much higher proportion of daily foraging time than nighttime foraging at high latitudes (Figs. $3 \& 4 \mathrm{~A}$ )

For ease of interpretation, we present the amount of light available per day in December across the range of latitudes (13 December; Fig. 5). Day length (daytime) is $7.25 \mathrm{~h}$ at $55^{\circ} \mathrm{N}$, decreases strongly with latitude and is 0 above $67.6^{\circ} \mathrm{N}$ (Fig. 5). Below $60^{\circ} \mathrm{N}$, both civil and nautical twilight is $<2 \mathrm{~h}$. Nautical twilight increases exponentially across the range of latitudes examined. Civil twilight increases strongly but reaches

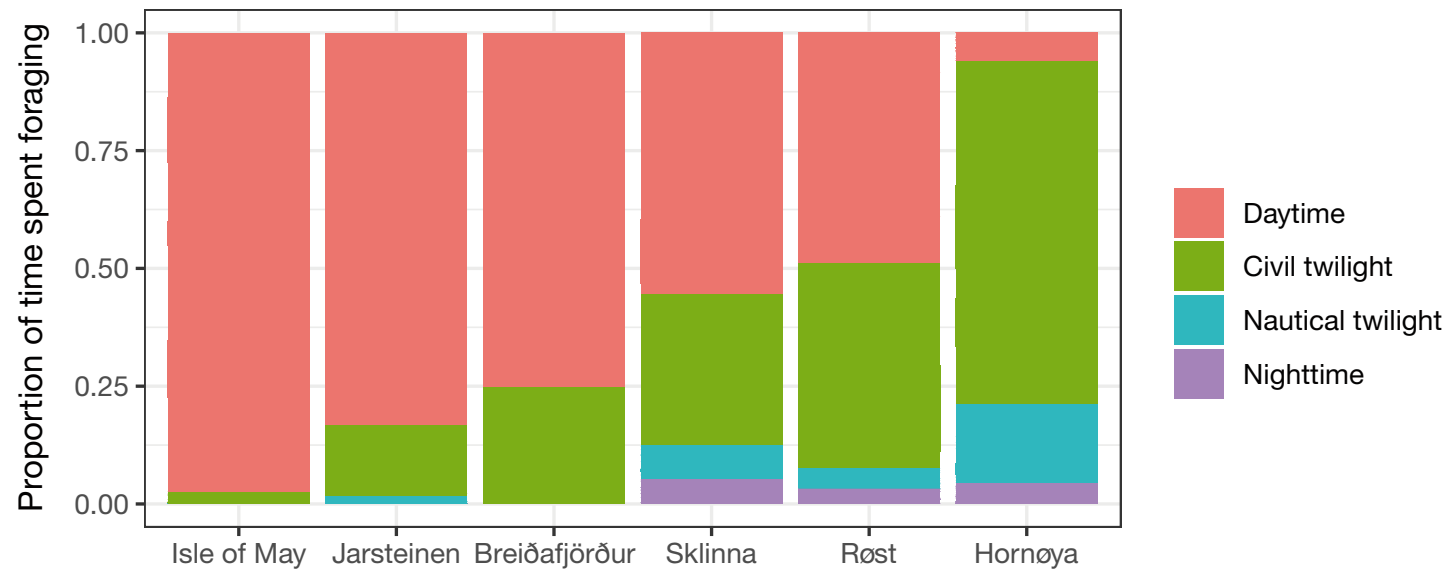

Fig. 3. Proportion of total time spent foraging per day in December by European shags. Colonies are ordered by increasing latitude 

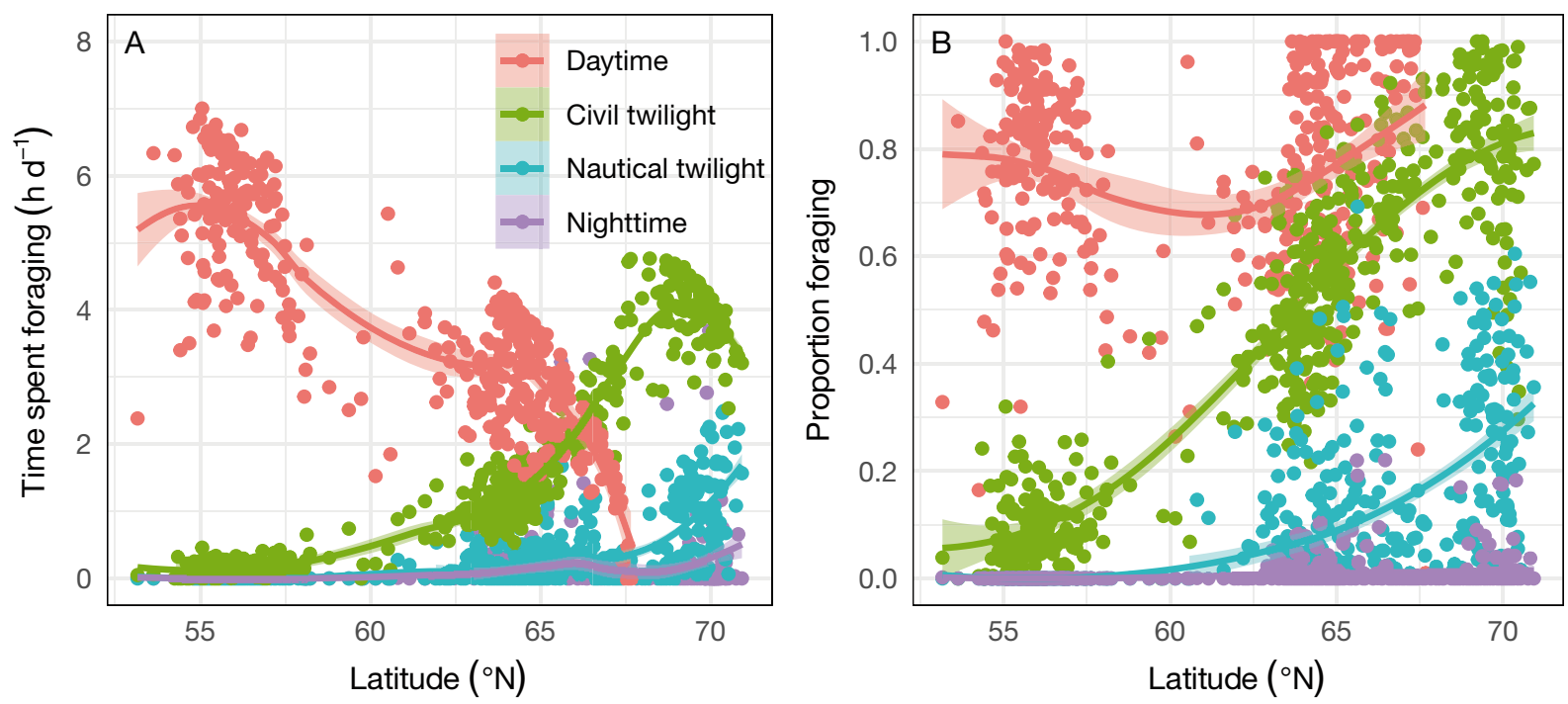

Fig. 4. (A) Time $\left(\mathrm{h} \mathrm{d}^{-1}\right)$ and (B) proportion of time spent foraging by European shags within each light category as a function of the birds' median latitude in December. Predictive lines and confidence intervals are plotted with the 'geom_smooth' function (span 0.5 and 0.9 in A and B, respectively) in 'ggplot2'

a maximum of $5.61 \mathrm{~h}$ at $67.7^{\circ} \mathrm{N}$ and then decreases (Fig. 5). Duration of nighttime in December ranges from 13.7 to $16.6 \mathrm{~h}$ between 55 and $71^{\circ} \mathrm{N}$.

\section{4. 'Feasting' hypothesis}

Total time spent foraging in December (hours per $24 \mathrm{~h}$ period, $\mathrm{h} \mathrm{d}^{-1}$ ) differed significantly among

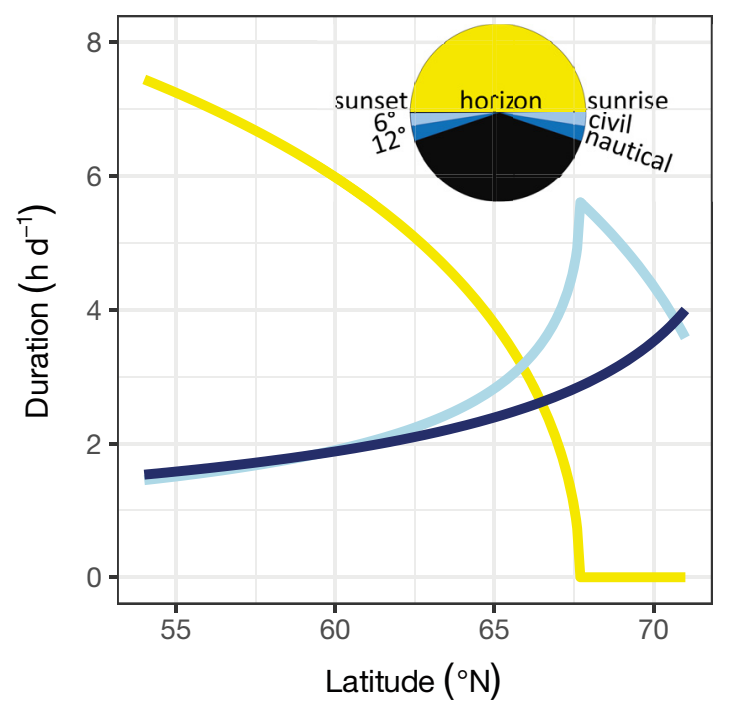

Fig. 5. Duration $\left(\mathrm{h} \mathrm{d}^{-1}\right)$ of daytime and twilight as a function of latitude in December. Duration was estimated for 13 December, representing the median December day length (winter solstice: 21 December). Daytime: sun is above horizon (yellow); civil (light blue) and nautical twilight (dark blue): sun $0-6$ and $6-12^{\circ}$ below the horizon, respectively colonies (LMM: $\mathrm{n}=487, \Delta \log \mathrm{Lik}=19.7, \Delta \mathrm{AIC}=29.3$, $\chi^{2}=39.3, \mathrm{df}=5, \mathrm{p}<0.001$; Figs. 6 \& 7). However, the results did not support the prediction that foraging time increases with decreasing latitude. Total time spent foraging was also not significantly related to median latitude in December (slope $-0.015 \pm 0.01 \mathrm{~h}$ $\mathrm{d}^{-1} \operatorname{deg}^{-1} ;$ LMM: $\mathrm{n}=487, \Delta \log \mathrm{Lik}=0.7, \Delta \mathrm{AIC}=0.6$, $\chi^{2}=1.46, \mathrm{df}=1, \mathrm{p}=0.2$; Fig. 7).

\section{DISCUSSION}

Long-lived species breeding at high latitudes, in particular those experiencing the polar night, must adopt behavioural strategies to counter the deteriorating environmental conditions in order to survive the winter. Across a species' latitudinal range, day length and light levels are 2 of the variables with the most striking variation and show systematic and predictable changes with latitude and season. Here, we examined 3 potential hypotheses for how shags adjust their behaviour in order to account for decreasing light levels in winter at high latitudes. Our results suggest that shags adopt a range of strategies that depend on the variable constraints of light on foraging time with latitude. We also found important variation between individuals at each colony, commensurate with shags being partial migrants across their range at varying scales and direction of migration.

We found partial support for the 'sun-chasing' hypothesis, with more extensive southerly movements in populations breeding at higher latitudes (Røst and 


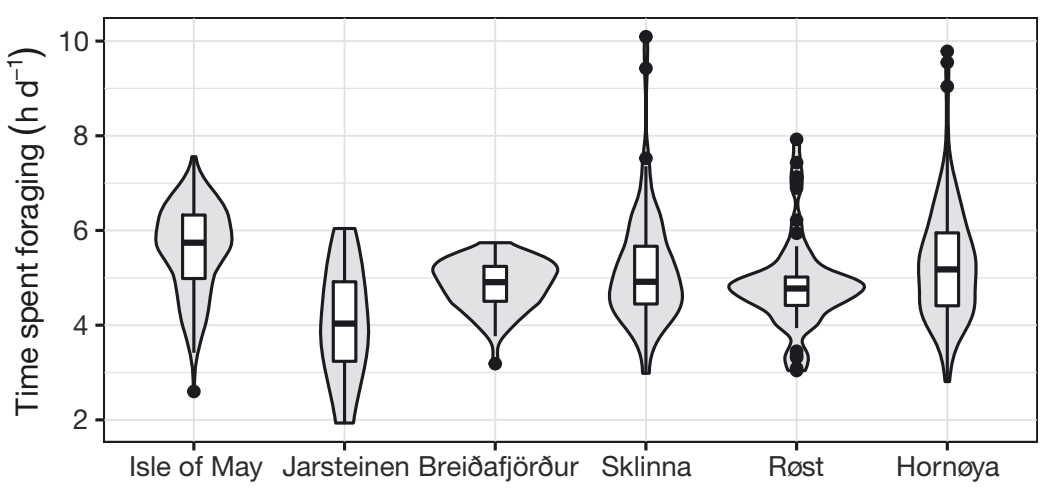

Fig. 6. Time spent foraging $\left(\mathrm{h} \mathrm{d}^{-1}\right)$ in December by European shags tracked with geolocators from the different study colonies (see Fig. 1). Colonies are ordered by increasing latitude. The violin plot shows the median of the data bound by an interquartile range (IQR) box, along with the kernel probability density of the data at different values. The vertical whiskers extend to the smallest or highest value within $1.5 \times$ IQR from the box, and points beyond the whiskers are outliers

Hornøya), as previously shown in the closely related great cormorant (White et al. 2013). This likely reflects the extreme reduction in light during the polar night, resulting in 98 and $15 \%$ of shags from these colonies, respectively, located south of the Arctic Circle $\left(67.6^{\circ} \mathrm{N}\right.$; Figs. $\left.1 \& 5\right)$ and experiencing some daylight in winter. Birds from Hornøya may have undertaken more restricted southerly movements, despite it being the more northerly of the 2 colonies, because of the need to move a substantial distance west in order to move south (Figs. $1 \& 2$ ), which may have been energetically costly. The reduced southerly movements at colonies of lower latitude may reflect the greater availability of light in midwinter (removing the necessity for substantial southerly movements). Further, birds from Jarsteinen actually showed a northerly migration on average, with very limited evidence of southerly movements. Findings from Isle of May shags, based on colour-ring sightings, show that a proportion of Isle of May breeders migrate a few hundred $\mathrm{km}$ north of the colony, experiencing shorter days in winter than those that remain resident (Grist et al. 2014, Acker et al. 2021). The movements of birds from these 2 southernmost study populations indicate that other factors may override the advantages of longer day length at those latitudes. An obvious possibility is that these birds are migrating north to areas of higher food availability or quality, and that habitat to the south may be less suitable for wintering shags. Shags come ashore to roost on land during the day and each night, so movements may be influenced by the availability of suitable roosting habitat as well as foraging habitat. It is highly probable that food and roost habitat availabil- ity is not clearly related to latitude. This availability may explain the variation around the trend between colony latitude and southerly migration distance that we observed. An additional factor in the case of Iceland is that shags rarely undertake long journeys across water, likely associated with their need to roost on land (Grémillet et al. 2005a), which limits these populations to localised migration movements. This lack of extensive sea crossings may also explain the absence of southerly movements for birds breeding at Jarsteinen. Indeed, all other populations occurred along extensive coastlines resulting in individuals having the option to migrate extensive distances south, and it appears that this option is important only to the most northerly populations in the study, as predicted by the 'sun-chasing' hypothesis.

Sun-chasing was not adopted by all individuals from the northernmost colonies; rather, it was apparent that their populations were partially migratory, as previously shown for Isle of May and Hornøya shags (Daunt et al. 2010, Grist et al. 2014). In the present study, $37 \%$ of individuals from Hornøya remained within $200 \mathrm{~km}$ of the breeding colony in December, and a further component of the population moved west along the northern coast of Norway, resulting in extensive migration distances but with limited changes in latitude (Fig. 1). Migration distance may be restricted by body condition, potentially hindering some individuals from reaching locations south of the Arctic Circle. Alternatively, local food availability

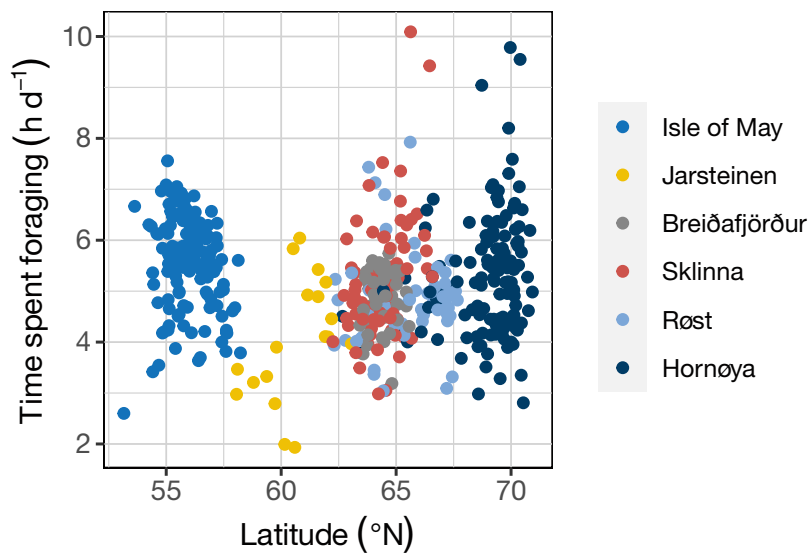

Fig. 7. Total time spent foraging $\left(\mathrm{h} \mathrm{d}^{-1}\right)$ by European shags in relation to median latitude in December. The colonies are identified by colours 
may be sufficient to preclude the need for such extensive southerly migrations for those individuals that locate these food sources. Clearly, all strategies can be successful, since our study relied on the retrieval of data loggers from birds returning the following or subsequent years to breed and therefore only includes surviving individuals. However, a future priority would be to ascertain whether these behavioural strategies are equally successful. To understand the demographic consequences of these strategies would require analyses that incorporate individuals that die (e.g. survival analyses of colourring resightings, Acker et al. 2021) and studies that quantify future breeding success in relation to migratory strategies, as have been undertaken on the Isle of May shag population (Grist et al. 2017) and in other seabirds (e.g. Bogdanova et al. 2017). Such studies would be informative for establishing the demographic and population dynamic consequences of these behavioural strategies.

We found little evidence that shags survive the winter at higher latitudes by foraging at night ('nightfeeding' hypothesis, Grémillet et al. 2005a). There was an absence of night-feeding at lower latitudes and some evidence of night-feeding at higher latitudes, but this was very limited. These results would appear to be in contrast to great cormorants wintering in northern Greenland, where extensive nighttime feeding has been recorded (Grémillet et al. 2005a). However, it is challenging to compare the studies since the cormorant study incorporated nautical twilight into the definition of night, which we avoided in order to explore the importance of twilight to winter foraging shags in more detail (Fig. 4). Our results appear more similar to twilight foraging shown in great cormorants and Steller's eiders Polysticta stelleri in northern Norway, which adjust their foraging times towards midday as winter progresses, in order to forage during twilight hours (Johansen et al. 2001, Systad \& Bustnes 2001). Indeed, shags in our study foraged extensively during civil twilight, closely reflecting the availability of civil twilight at different latitudes (i.e. increasing proportionally with latitude before declining north of $67.7^{\circ} \mathrm{N}$; Figs. $4 \mathrm{a}$ \& 5). Shags foraged to a lesser extent during nautical twilight, but foraging exponentially increased above $67.7^{\circ} \mathrm{N}$ to compensate for the declining civil twilight. Foraging in both twilight categories, thus, seems increasingly important for winter survival of shags with increasing latitude. Although individuals from populations at higher latitudes that remain north of the Arctic Circle lose all daylight in winter, there appears to be sufficient twilight for them to find the food that they require to survive, without the need to feed extensively at night. Southerly populations have sufficient daylight in winter to forage, with limited evidence of twilight feeding. Thus, shags appear to survive across their latitudinal range based on sufficient availability of daylight or twilight. This finding provides a solution to the apparent paradox of how shags survive at higher latitudes even though past work has demonstrated that they are visual foragers (Wanless et al. 1999), and those in temperate regions use $>90 \%$ of daylight for foraging in midwinter (Daunt et al. 2006, 2014). Shags may adjust their diving behaviour to lower light levels during twilight in winter at higher latitudes by foraging at shallower depths, as shown in great cormorants wintering in Greenland (White et al. 2008). The diurnal patterns of foraging depth during the breeding season, with shallower dives occurring during the darkest periods of the day (Wanless et al. 1999), provides further support for this theory. Alternatively, shags may use tactile foraging to capture prey at low light levels in winter. Work on great cormorants has demonstrated that they have comparatively poor sight underwater, suggesting that they may disturb and capture prey when cruising along the seafloor, using sudden head and neck movements as opposed to longer pursuits, allowing them to capture prey at low light levels (Martin et al. 2008, Grémillet et al. 2012). Further work on the 3-dimensional underwater movements of shags would help ascertain how they forage successfully in twilight in winter at high latitudes, but it seems clear that they have behavioural strategies that ensure they obtain enough food outside the long periods of total darkness to survive the winter season.

A negative relationship between latitude and foraging time would have provided evidence for the 'feasting' hypothesis, whereby individuals breeding at high latitudes survive the winter by targeting higher-quality food patches that ensure that daily food requirements are obtained in the shorter periods of adequate light (Grémillet et al. 1999, White et al. 2013). However, we found no relationship between December latitude and foraging time across our study populations; rather, foraging time was lowest at intermediate latitudes. This pattern may have been caused by local variation in climatic and oceanographic conditions (weakly or not related to latitude) resulting in heterogeneity in food availability across a species' range. Alternatively, if light levels result in less constraint on foraging by birds at lower latitudes, shags from the southern colonies of Jarsteinen and the Isle of May may be able to migrate north to loca- 
tions with shorter days than at the breeding colony in winter. The region located around $62-63^{\circ} \mathrm{N}$ appears to be important for shags, forming a boundary between the southern limit of individuals migrating south from northern Norwegian colonies and the northern limit of individuals migrating north from Jarsteinen (Fig. 1). This boundary may divide 2 regions with differing ecosystem conditions in the North Sea and the Norwegian Sea (Brattegard \& Holthe 1995). Shags from Røst and Sklinna primarily feed on age 0 and 1 saithe of the NE Arctic stock during the breeding season (Hillersøy \& Lorentsen 2012, Lorentsen et al. 2015, T. Anker-Nilssen unpubl. data), so it might be a successful strategy for them to stay north of the boundary and exploit the same prey in winter. Correspondingly, the winter distribution of Jarsteinen birds in the present study indicates they are likely dependent on fish from North Sea stocks (including saithe; Barrett et al. 1990) both during summer and winter. Winter admixing of multiple shag populations at important foraging grounds may also disrupt simple correlations between migration distance, foraging effort and colony latitude. European populations of black-legged kittiwakes Rissa tridactyla show strong winter aggregation in the western Atlantic, resulting in marked differences migration distances (Frederiksen et al. 2012, Bogdanova et al. 2017). Similarly, evidence of overlapping wintering ranges of the northern Norwegian shag colonies was seen in the present study. An analysis of diet and foraging efficiency would be required to establish the relative profitabilities of different regions to populations of shags adopting different behavioural strategies. Shags resident on the Isle of May have a similar diet in winter and summer (Howells et al. 2017, 2018). However, there is limited understanding of winter diet at other colonies. This absence of knowledge hinders future analyses that would ideally aim to predict the availability of predominant prey as well as the costs of foraging, which are closely related to temperature and therefore vary with location. If such data were available, more refined 'feasting' hypotheses could be tested that incorporate environmental conditions and associated costs as well as latitude (Cavallo et al. 2020).

\section{CONCLUSIONS}

The success of shag behavioural strategies in winter will be dependent on the location of high-quality and/or abundant food in winter, its location relative to the breeding colony, the costs of migration and the prevailing light and climatic conditions that will affect the birds' ability to profit from such opportunities. These trade-offs dictate the variety of behavioural strategies that our study populations adopted across a marked latitudinal range. In particular, a proportion of individuals at higher latitudes migrate to areas where there is a greater availability of light, and northern populations make use of extensive twilight periods to forage in winter in the absence of daylight, precluding the need to forage at night. However, these patterns with latitude were not observed at all colonies, with some reversing the trend indicating that shags may be migrating to attain better access to food regardless of less favourable light levels and day length at their destination. Thus, there appears to be heterogeneity in food availability in winter that does not correlate closely with latitude, which is potentially why we found no clear evidence for the 'feasting' hypothesis. Our study provides important insights for understanding range-wide population persistence in seabird species that are distributed across a latitudinal gradient. Our results also highlight the value of multicolony studies when investigating behavioural strategies for winter survival. Further work that incorporates analyses of energetics and demography of individuals adopting different strategies within and between colonies would be informative in establishing the causes and consequences of winter migration strategies across the species' range.

Acknowledgements. This work is part of SEATRACK (https://seapop.no/en/seatrack/) and was funded by the Norwegian Ministry of Climate and Environment, the Norwegian Ministry of Foreign Affairs and the Norwegian Oil and Gas Association along with 8 oil companies. The Norwegian part of the study was also part of SEAPOP, which is financed by the Norwegian Ministry of Climate and Environment through the Norwegian Environment Agency, the Norwegian Ministry of Petroleum and Energy through the Norwegian Research Council (grant no. 192141) and the Norwegian Oil and Gas Association. This work was also supported by NERC funding for UK National Capability including award number NE/R016429/1 as part of the UK$\mathrm{SCaPE}$ programme. We thank NatureScot for permission to work on the Isle of May National Nature Reserve. This work was also supported by a grant (232019) from the Fram Centre flagship 'Climate Change in Fjord and Coast' to B.M. We are grateful to all field workers involved in collecting the data in all the colonies. Norwegian Food Safety Authority provided permissions to deploy loggers in Norway.

\section{LITERATURE CITED}

Acker P, Daunt F, Wanless S, Burthe SJ and others (2021) Strong survival selection on seasonal migration versus residence induced by extreme climatic events. J Anim Ecol 90:796-808 
Bakken V, Runde O, Tjørve E (2003) Norsk ringmerkingsatlas, Vol 1. Stavanger Museum, Stavanger

Barrett RT, Røv N, Loen J, Montevecchi WA (1990) Diets of shags Phalacrocorax aristotelis and cormorants P. carbo in Norway and possible implications for gadoid stock recruitment. Mar Ecol Prog Ser 66:205-218

Bogdanova MI, Butler A, Wanless S, Moe B and others (2017) Multi-colony tracking reveals spatio-temporal variation in carry-over effects between breeding success and winter movements in a pelagic seabird. Mar Ecol Prog Ser 578:167-181

Bråthen VS, Moe B, Amélineau F, Ekker $M$ and others (2021) An automated procedure (v2.0) to obtain positions from light-level geolocators in large-scale tracking of seabirds. A method description for the SEATRACK project. NINA Report 1893. Norwegian Institute for Nature Research, Trondheim. https://brage.nina.no/nina-xmlui/ handle/11250/2735757

Brattegard T, Holthe T (eds) (1995) Kartlegging av egnede marine verneområder i Norge. Tilrådning fra rådgivende utvalg. DN utredning 1995-3. Norwegian Directorate for Nature Management, Trondheim

Brooks ME, Kristensen K, van Benthem KJ, Magnusson A and others (2017) glmmTMB balances speed and flexibility among packages for zero-inflated generalized linear mixed modelling. R J 9:378-400

Cavallo C, Chiaradia A, Deagle BE, Hays GC and others (2020) Quantifying prey availability using the foraging plasticity of a marine predator, the little penguin. Funct Ecol 34:1626-1639

Chapman BB, Brönmark C, Nilsson J, Hansson L (2011) The ecology and evolution of partial migration. Oikos 120: 1764-1775

Daunt F, Afanasyev V, Silk JRD, Wanless S (2006) Extrinsic and intrinsic determinants of winter foraging and breeding phenology in a temperate seabird. Behav Ecol Sociobiol 59:381-388

Daunt F, Barrett RT, Anker-Nilssen T (2010) Winter distribution and foraging strategies of European shags. SEAPOP Short Report 3-2010. Norwegian Institute for Nature Research, Trondheim. https://seapop.no/wp-content/ uploads/2021/03/seapop-short-report-3-2010.pdf

Daunt F, Reed TE, Newell M, Burthe S, Phillips RA, Lewis S, Wanless S (2014) Longitudinal bio-logging reveals interplay between extrinsic and intrinsic carry-over effects in a long-lived vertebrate. Ecology 95:2077-2083

Douglas B, Maechler M, Bolker B, Walker S (2015) Fitting linear mixed-effects models using lme4. J Stat Softw 67:1-48

Egevang C, Stenhouse IJ, Phillips RA, Petersen A, Fox JW, Silk JRD (2010) Tracking of Arctic terns Sterna paradisaea reveals longest animal migration. Proc Natl Acad Sci USA 107:2078-2081

Fauchald P, Anker-Nilssen T, Barrett RT, Bustnes JO and others (2015) The status and trends of seabirds breeding in Norway and Svalbard. NINA Report 1151. Norwegian Institute for Nature Research, Trondheim. https://brage. nina.no/nina-xmlui/handle/11250/2397703

Fayet AL, Freeman R, Anker-Nilssen T, Diamond A and others (2017) Ocean-wide drivers of migration strategies and their influence on population breeding performance in a declining seabird. Curr Biol 27:3871-3878

Fort J, Moe B, Strøm H, Grémillet D and others (2013) Multicolony tracking reveals potential threats to little auks wintering in the North Atlantic from marine pollution and shrinking sea ice cover. Divers Distrib 19:1322-1332
Fox J (2010) Geolocator manual v8. British Antarctic Survey, Cambridge

Fox J (2015) Intiproc geolocation processing software. User reference manual Intiproc v1.03 (January 2015). Migrate Technology, Cambridge

Frederiksen M, Moe B, Daunt F, Phillips RA and others (2012) Multicolony tracking reveals the winter distribution of a pelagic seabird on an ocean basin scale. Divers Distrib 18:530-542

F Frederiksen M, Descamps S, Erikstad KE, Gaston AJ and others (2016) Migration and wintering of a declining seabird, the thick-billed murre Uria lomvia, on an ocean basin scale: conservation implications. Biol Conserv 200: 26-35

Gilg O, Moe B, Hanssen SA, Schmidt NM and others (2013) Trans-Equatorial migration routes, staging sites and wintering areas of a high-Arctic avian predator: the long-tailed skua (Stercorarius longicaudus). PLOS ONE 8:e64614

Grémillet D, Wilson RP, Wanless S, Peters G (1999) A tropical bird in the Arctic (the cormorant paradox). Mar Ecol Prog Ser 188:305-309

* Grémillet D, Kuntz G, Gilbert C, Woakes AJ, Butler PJ, Le Maho Y (2005a) Cormorants dive through the Polar night. Biol Lett 1:469-471

* Grémillet D, Chauvin C, Wilson RP, Le Maho Y, Wanless S (2005b) Unusual feather structure allows partial plumage wettability in diving great cormorants (Phalacrocorax carbo). J Avian Biol 36:57-63

* Grémillet D, Nazirides T, Nikolaou H, Crivelli AJ (2012) Fish are not safe from great cormorants in turbid water. Aquat Biol 15:187-194

Grist H, Daunt F, Wanless S, Nelson EJ and others (2014) Site fidelity and individual variation in winter location in partially migratory European shags. PLOS ONE 9: e98562

* Grist H, Daunt F, Wanless S, Burthe SJ, Newell MA, Harris MP, Reid JM (2017) Reproductive performance of resident and migrant males, females and pairs in a partially migratory bird. J Anim Ecol 86:1010-1021

*Hanssen SA, Gabrielsen GW, Bustnes JO, Bråthen VS and others (2016) Migration strategies of common eiders from Svalbard: implications for bilateral conservation management. Polar Biol 39:2179-2188

Hijmans RJ (2020) raster: geographic data analysis and modeling. $\mathrm{R}$ package version 3.4-5. https://CRAN.Rproject.org/package=raster

Hill RD (1994) Theory of geolocation by light levels. In: Le Boeuf BJ, Laws RM (eds) Elephant seals: population ecology, behaviour and physiology. University of California Press, Berkeley, CA, p 227-236

Hillersøy G, Lorentsen SH (2012) Annual variation in the diet of breeding European shag (Phalacrocorax aristotelis) in Central Norway. Waterbirds 35:420-429

Howells RJ, Burthe SJ, Green JA, Harris MP and others (2017) From days to decades: short- and long-term variation in environmental conditions affect offspring diet composition of a marine top predator. Mar Ecol Prog Ser 583:227-242

Howells RJ, Burthe SJ, Green JA, Harris MP and others (2018) Pronounced long-term trends in year-round diet composition of the European shag Phalacrocorax aristotelis. Mar Biol 165:188

Johansen R, Barrett RT, Pedersen T (2001) Foraging strategies of great cormorants Phalacrocorax carbo carbo wintering north of the Arctic Circle. Bird Study 48:59-67 
Kuznetsova A, Brockhoff PB, Christensen RHB (2017) lmerTest package: tests in linear mixed effects models. J Stat Softw 82:1-26

Lack D (1968) Behavioural adaptations for breeding in birds. Methuen, London

Lilliendahl K, Solmundsson J (2006) Feeding ecology of sympatric European shags Phalacrocorax aristotelis and great cormorants P. carbo in Iceland. Mar Biol 149:979-990

Lisovski S, Hahn S (2012) GeoLight-processing and analysing light-based geolocator data in R. Methods Ecol Evol 3:1055-1059

Lorentsen SH, Anker-Nilssen T, Erikstad KE, Røv N (2015) Forage fish abundance is a predictor of timing of breeding and hatching brood size in a coastal seabird. Mar Ecol Prog Ser 519:209-220

Martin GR, White CR, Butler PJ (2008) Vision and the foraging technique of great cormorants Phalacrocorax carbo: pursuit or close-quarter foraging? Ibis 150:485-494

McFarlane Tranquilla LA, Montevecchi WA, Hedd A, Fifield DA and others (2013) Multiple-colony winter habitat use by murres Uria spp. in the Northwest Atlantic Ocean: implications for marine risk assessment. Mar Ecol Prog Ser 472:287-303

Murphy R, Perry E, Keisman J, Harcum J, Leppo EW (2020) baytrends: long term water quality trend analysis. R package version 1.2.1. https://CRAN.R-project.org/package= baytrends

Newton I (1998) Population limitation in birds. Academic Press, London

NOAA (2020) Definitions of twilight. National Weather Service, Forecast Office, Sioux Falls, SD. www.weather. gov/fsd/twilight (accessed 20 May 2020)

Phillips RA, Silk JRD, Croxall JP, Afanasyev V, Briggs DR (2004) Accuracy of geolocation estimates for flying seabirds. Mar Ecol Prog Ser 266:265-272

R Core Team (2020) R: a language and environment for statistical computing. R Foundation for Statistical Computing, Vienna

Ropert-Coudert Y, Kato A, Poulin N, Grémillet D (2009) Legattached data loggers do not modify the diving performances of a foot-propelled seabird. J Zool (Lond) 279: 294-297

Stearns SC (1992) The evolution of life histories. Oxford University Press, Oxford

Stenhouse IJ, Egevang C, Phillips RA (2012) Trans-equatorial

Editorial responsibility: Stephen C. Votier (Guest Editor), Cornwall, UK

Reviewed by: K. Ludynia and 2 anonymous referees migration, staging sites and wintering area of Sabine's gulls Larus sabini in the Atlantic Ocean. Ibis 154:42-51

Systad GH, Bustnes JO (2001) Coping with darkness and low temperatures: foraging strategies in Steller's eiders, Polysticta stelleri, wintering at high latitudes. Can J Zool 79:402-406

Thieurmel B, Elmarhraoui A (2019) suncalc: compute sun position, sunlight phases, moon position and lunar phase. $\mathrm{R}$ package version 0.5.0. https://CRAN.R-project.org/ package $=$ suncalc

van Bemmelen RSA, Moe B, Hanssen SA, Schmidt NM and others (2017) Flexibility in otherwise consistent nonbreeding movements of a long-distance migratory seabird, the long-tail skua. Mar Ecol Prog Ser 578:197-211

* van Bemmelen RSA, Kolbeinsson Y, Ramos R, Gilg O and others (2019) A migratory divide among red-necked phalaropes in the Western Palearctic reveals contrasting migration and wintering movement strategies. Front Ecol Evol 7:86

Wanless S, Harris MP (1997) Phalacrocorax aristotelis. Shag. BWP Update 1:3-13

*Wanless S, Finney SK, Harris MP, McCafferty DJ (1999) Effect of the diel light cycle on the diving behaviour of two bottom feeding marine birds: the blue-eyed shag Phalacrocorax atriceps and the European shag $P$. aristotelis. Mar Ecol Prog Ser 188:219-224

*White CR, Butler P, Grémillet D, Martin GR (2008) Behavioural strategies of cormorants (Phalacrocoracidae) foraging under challenging light conditions. Ibis 150: 231-239

*White CR, Grémillet D, Green JA, Martin GR, Butler P (2011) Metabolic rate throughout the annual cycle reveals the demand of an Arctic existence in great cormorants. Ecology 92:475-486

*White CR, Green JA, Martin GR, Butler PJ, Grémillet D (2013) Energetic constraints may limit the capacity of visually guided predators to respond to Arctic warming. J Zool (Lond) 289:119-126

Wickham H (2016) ggplot2: elegant graphics for data analysis. Springer-Verlag, New York, NY

Wilson RP, Ducamp JJ, Rees G, Culik BM, Niekamp K (1992) Estimation of location: global coverage using light intensity. In: Priede IM, Swift SM (eds) Wildlife telemetry: remote monitoring and tracking of animals. Ellis Horward, Chichester, p 131-134

Submitted: August 31, 2020

Accepted: March 12, 2021

Proofs received from author(s): June 29, 2021 